\title{
Environmentally friendly wetlands management for tourism
}

\author{
M. Khoshkam \& A. Marzuki \\ School of Housing, Building and Planning, Universiti Sains, Malaysia
}

\begin{abstract}
The complex relationship between residents and wetland areas continues to be an obstacle to the successful use of the natural environment. A key component of this relationship is the lack of local residents' training about wetland areas and lack of knowledge regarding the use of conservation areas. This study reviews the theoretical and empirical issues of the relationship between training locals to be environmentally friendly and the natural ecosystem. It explores studies by other researchers in regard to domestic and international tourists' attitudes towards those areas. This study will show the role of training locals how to increase their skills in relation to environmentally friendly tasks. Cultural and natural resources can make residents responsible and environmentally educated. The objective of this study was to provide opportunities for community involvement in protected areas such as wetlands. Results support previous assertions about residents' training and its relationship with environmentally friendly behaviour and increasing the number of tourists in the wetlands. The evaluation asserted that understanding and developing institutional resources by residents could encourage them to be environmentally friendly and encourage tourism development in wetlands.
\end{abstract}

Keywords: residents' training, wetlands, environmentally friendly.

\section{Introduction}

In recent decades the study of residents' use of wetlands has undergone a major change. Wetlands and water resources have played a key role in human life. Wetlands as a natural resource have two types: natural and constructed. Natural wetlands are in natural areas where water covers the soil. Constructed wetlands have a similar ecosystem structure concerning the combination of biological and 
chemical processes [1]. Therefore, many wetlands with a large number of resident/tourist activities can be found around the world. Activities include fishing, water skiing and boating. Boating in the wetlands can also create pollution in different areas. Therefore, choosing a boat is important in minimising pollution in the wetlands so everyone can enjoy these areas. These natural resources need protection so future generations can enjoy them [2]. The value of wetlands with different services and functions in the community needs to be endorsed [3]. For that reason, the wise use of wetlands refers to the sustainable use of wetlands for each activity. Also, preserving the integral, biological and fundamental balance of the wetlands is also needed. Providing information for everyone who wants to know about wetland wise use can create a win-win situation. Understanding the ecosystem depends on its individual parts, and changing or removing each part of it, like dominos, will affect other parts. Therefore, it is important to implement wise use strategies [2].

Apart from protected areas, many lakes, rivers, lagoons, swamps, marshes and particularly wetlands cater to leisure and entertainment activities. The number of these areas also indicates the consideration of wetland tourism in each country's economy and culture. The infrastructure of these conservational areas consists of the sensitive habitats of fauna and flora. They are one of the most significant aspects of wetland ecotourism activities for domestic or international tourists.

An environmentally friendly tourism industry will embrace the natural sources and environment. It will conduct activities in such a manner to leave few negative impacts. Thus, the term "environmentally friendly tourism" and "nature-based tourism" will incorporate the support of preservation areas and understanding of the natural environment. This type of tourism as mentioned before will promote conservation of the environment. Environmentally friendly tourism can include three dimensions of tourism: cultural/heritage tourism, ecotourism and wildlife tourism. Although other kinds of tourism can be included in this category, they are related to these major dimensions (e.g., rural tourism, adventure tourism). Another type of tourism is "responsible tourism" that can provide various benefits for tourists, host communities and governments. Some of the best promotion of environmentally friendly tourism includes environmental conservation, economic and political empowerment of local populations, environmental conservation, cultural protection and international understanding and support. When this mission is fulfilled, it not only has minimal impacts, but also the residents' environment and local community can receive benefits from the experience and control of it [4]. Thus, being aware of residents' perceptions and preparing them for tourism development and the impacts behind it can help planners and decision-makers recognise real concerns and statements so different policies and action can occur to minimise troubles and optimise benefits [5].

Regarding tourism development in different areas, different models have been developed by different researchers, such as the Butler lifecycle model in 1980 that included five stages of tourism development (exploration, involvement, development, consolidation, and stagnation and decline or rejuvenation). These stages are equal to the stages of Doxey's "Irridex" model. The attitudes of 
residents seen through a predictable progression of reactions (from euphoria to apathy to annoyance to antagonism) are related as the community moves through the first stages of tourism development [6-7]. Previously mentioned statements reveal the purpose of this article was to provide wise use opportunities for local communities in protected areas, particularly wetlands. Therefore, training local community and residents in conservation can result in the wise use of wetlands. On the other hand, residents' knowledge is significant for environmentally friendly tourism to succeed. This paper reviews four aspects of knowledge about the wise use of wetlands: residents' training, definitions of wetland, definition of the wise use of wetland and environmentally friendly behaviour regarding tourism development. This paper offers insight from a review of environment and wetland studies and the broader effort of environmental-friendly tourism development and its relationship to training residents. This paper also reviews residents' knowledge gaps towards environmentally friendly behaviour in wetlands.

\section{Residents' training}

In each industry where public image is key to accomplishment, local communities and tourists need information about what is being done to ensure a healthy and friendly environment. However, the pollution of natural resources is caused by infrastructure development or lack of appropriate maintenance. Therefore, public training with regard to this information should be done so education of the local residents and visitors can provide more support for natural resources such as marine, coastal areas and wetlands [8]. This approach can provide the first step towards awareness and training of residents and tourists in natural areas. It is important to recognise that having experts conduct the training can improve training. They are educated in a basic level of related skills, which can help them know what travelers need and help them provide a high quality of training. Although these managers and experts may need education and experience, agencies, organisations and businessmen in the travel industry can help provide that. Based upon the discussion, different plans should be made for each level. It is the reason why each component of the tourism industry needs training. The training programs in the tourism industry include accommodation, transportation systems, parks, recreational services and historical monuments. In each community, citizens in the host region or country interact with domestic or international tourists in different ways. Local residents have direct contacts with tourists and they are major sources of information and guidelines [9]. Consequently, managers and planners should define education and training tactics for locals in the wise use of wetlands.

\subsection{Training residents in the wise use of wetlands}

In most human history, relationships between humans and nature are obvious, and little knowledge among residents about resource use is one of the most significant problems [10]. Training, with the aim of developing skills that can 
educate everyone who wants to know everything, should start with understanding reasons behind the issues and needed tasks. Therefore, training that overlaps different educational processes, environmental awareness and commitment are among the significant products of environmental training [11]. Consequently, the role of training in planning environmental tourism will focus on the awareness and knowledge of the residents, particularly in community education [4]. Residents often have an understanding of wetland ecology in a context that is far subtler or usually superior to outsider "experts." Their practice of charitable restrictions on use and access can be invaluable tools for wetland management [12]. Recreational activities surrounding wetlands are an essential component in the wise use of the area, and they play a key role (e.g. fish population) for the local residents [13]. A large number of non-governmental organisations (NGOs) have started training residents in each community as a fundamental component of conserving areas such as wetlands. Experience has shown that environmental tourism is conducted by local people in conservation areas. With their skills they can act as tour guides and gate keepers [4]. However, in each field of study, especially about wetlands, there is a lack of answers about achieving the wise use of them. Wise use in certain conditions or in a particular wetland can change; therefore, wise use can change to unwise use. Wood et al. has argued that local communities have the knowledge to build up soil and hydrology conditions in conservation areas, and they have managed the area well enough to allow longtime use without degradation. The study also pointed out different policies of decision-makers regarding the diversity of local conditions in the wetlands and their associated communities [14]. Consequently, wise use focuses on the question of organising, changing, verifying, thinking and finally planning for actual use by itself [15].

\subsection{Environmentally friendly tourism}

Concentrating on tourism in conservation areas with regard to the types of residents/tourists in protected areas, particularly wetlands, is the other discussion that could have benefits by increasing the number of tourists who feel wise use is important. There has been a steady increase in the number of visits in protected areas and natural resources. The annual growth rate of tourists was shown during the last decades; the percentage growth was between $10 \%$ and $30 \%$, and it represented approximately $20 \%$ of all travel in the world [16]. Environmentally friendly tourism also aims "...to promote sustainable development and ecofriendly travel by providing programs that help travelers and travel-related companies protect the environmental, socio-cultural and economic needs of the places they visit, and the planet at large" [17]. Moreover, protecting both cultural and natural tourism resources for recent and next generations can be guaranteed [18]. A recent study involved definition and operationalisation of the different studies regarding environmentally friendly tourists/tourism in different sustainable tourism and ecotourism features. These researchers categorised their review of some articles regarding environmentally friendly tourism/tourists with seventeen factors including a natural location and most frequently used. Another common factor was "learning about nature." Interestingly, the other factors were 
categorised as regular percentages and used. Accordingly, "other factors after two significant mentioned ones are 'conservation of nature,' appreciation of nature, cultural interaction, understanding location, experiencing nature, protection of nature, length of trip, economic contribution to host community, nature based, sustainability of nature, physical activities, understanding nature, escape from pressured pace of living, observation of nature and finally interacting with nature" [18]. Hence, they believe that the second feature, "learning about nature," is one of the most intense reactions following environmentally friendly tourism. Research on this definition is needed to facilitate training about environmentally friendly behaviour that may support sustainable tourist destinations and maintain tourist attractions.

\section{Definitions of wetlands}

Regional and local names for wetlands reflect the structure of them according to their position and recognition. In the United States and Europe there are more various definitions of wetlands, especially in European countries. Therefore, wetlands with interesting formations attracted scientific wisdom in the middle of the nineteenth century. The first systematic definition of wetland was reported by the Ramsar Convention, Iran, in 1971, and referred to wetlands as "....areas of marsh, fen, peatland or water, whether natural or artificial, permanent or temporary, with water that is static or flowing, fresh, brackish, or salt, including areas of marine waters, the depth of which at low tide does not exceed six meters." Also, wetlands include “.... riparian and coastal zones adjacent to wetlands, or islands or bodies of marine water deeper than six meters at low tide lying within" [19]. In the last four decades the rate of destruction among wetlands has accelerated, and in this century wetlands are consumed primarily for urbanisation and tourism development. These natural resources were tainted and reduced through inflow and infilling as a result of urban pollution, industrial sewage and agriculture. Other activities surrounding wetlands such as overhunting, overfishing and visitors entertainment also deprived wetlands of their functions [15]. Thus, the responsibility and awareness of local people and tourists in wetlands as well as their functions can bring about opportunities for wise use of wetlands as natural resources.

\subsection{Wise use of wetlands communication and awareness framework}

The term "wise use of wetlands" was interpreted in the first conference at Cagliari in 1980. The term was defined as the conservation of the wetlands without destruction and pollution. At the time, the statement referred to wetlands in developing countries and countries with a rural economy. Because of these positions those wetlands were sources of productivity and hydrological resources. Therefore, with this term Cagliari's concern was wetland conservation. The concept of wise use under the Ramsar Convention is more precise and broadens it. In 1987, the Regina Conference defined the wise use of wetlands as "their sustainable utilization for the benefit of humankind in a way 
compatible with the maintenance of the natural properties of the ecosystem." The regular definition that emerged from this statement is "Sustainable Utilization" and includes "human use of a wetland so that it may yield the greatest continuous benefit to present generations while maintaining its potential to meet the needs and aspiration of future generations" [20]. The previously mentioned wetland resources are a global wealth of enormous flora and fauna to present to future generations, which are crucial for social and economic development. Wetland conservation incorporates preservation, sustainable utilisation, restoration and improvement of natural resources [3]. Based on the perspectives and statements of the wetlands and wise use, the role of the community and local people who surround the wetlands is vital, so the importance of local knowledge and local practices is appreciated in the wise use of wetland resources.

Ramsar cites educational and scientific studies that support infrastructure development for certain uses of these sites. One example is low-impact tourism, which can provide conservation and economic benefits. It is among the ways local residents can benefit from the Ramsar sites and other conservation areas while giving those sites a successful opportunity for site improvement and maintenance [21].

To clarify these statements a framework was prepared (Figure 1) with three factors that can complete the relationship between residents and wise use of wetlands. These factors include awareness as described previously with residents training and knowledge in the local community. The second part is wise use with increasing responsibility and support of the wetlands. The third part, environmentally friendly, includes different aspects such as reducing conflict and exploitation between residents/tourists and wetlands, wise use of wetlands, interacting in a friendly manner with the wetlands, realising potential benefits, and tourism development with wise use and "sustaining utilization" concerning the wise use of wetlands.

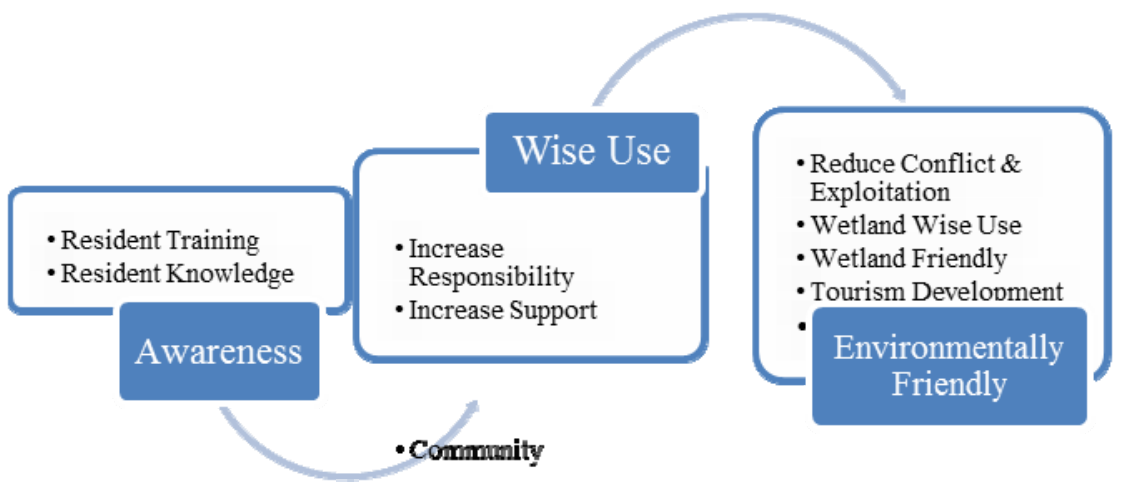

Figure 1: The different factors of training residents on wise use of wetlands. 


\section{Environmentally friendly behaviours and tourism development}

The nature of research about environmentally friendly tourists goes back to the term and learning about how residents/tourists behave with natural resources. Learning about personal traits can help sustainable tourism and tourism development in nature destinations. Tourists in natural environments can minimise their impact, but they destroy and damage natural environments more than in urban locations or other tourism destinations. The context of nature-based tourism extends to the potential of tourists to understand environmentally friendly attitudes [18]. The vitality of environmentally friendly tourists was empirically measured for the purpose of knowledge evaluation. Therefore, researchers demonstrated the different impacts of operationalisation concerning environmentally friendly tourists [22]. Accordingly, there are advantages and disadvantages to environmentally friendly tourist behaviour. Two groups in an ecotourism operation are referred to here: ecotourists and environmentally friendly tourists. Disadvantages of this approach come up because different types of environmentally friendly tourists are not captured and are not clear when organising tourists with environmentally friendly behaviour. They are all categorised with a "green" label [18]. Ecotourists visit the natural resources but have no financial stake in them. This was the result of studies of serious wetland visitors who traveled to Taiwan to study environmentally friendly tourists. Ecotourists do like to "help tourists to learn about the wetland" [23]. The study posits that environmentally friendly behaviour affects the relationship between antecedent variables and intention towards training and preparing residents for wise use of wetlands. The paths would be stronger for high wise use or low wise use with environmentally friendly behaviour of wetland and tourism development because they would indicate that residents who actively practice training and awareness regarding wise use are more inclined to provide environmentally friendly services with wetlands compared to residents who are not trained.

\section{Conclusions and recommendation}

Exploring the declarations regarding environmentally friendly behaviour can draw a relationship between the wise use of wetlands and training residents. This is because training residents will make a positive impact on tourists' behaviour and their relationship with the natural environment, particularly wetlands. Numerous studies support the idea of training residents about the potential benefits of wetlands wise use, which in turn creates environmentally friendly behaviour, thereby increasing the number of tourists who visit wetlands. Wise use of wetlands will create opportunities for tourism development and reduce the negative impacts of tourism. Knowledge about rules and characteristics of wetlands can bring about support from the local community. The community will increase its responsibilities for wise use of wetlands to achieve environmentally friendly behaviour. Sustainable management of protected areas 
could reduce conflict among nature, humans and exploitation. Knowledgeable people who protect conservation areas can be another result that arises among residents. Therefore, environmentally friendly behaviour will increase the number of tourists who visit the wetlands. Overall, the evaluation includes understanding and developing the institutional resources among residents that could encourage them to be environmentally friendly by way of wise use towards tourism development in wetlands. Moreover, in 1980 the support of appropriate training was recommended by international organisations to the Ramsar Convention to enable developing countries to be taught the proper implementation of wetlands by development agencies. Training and education were applied along with project personnel. After the project, personnel recommended educational strategies be developed at a school/university as well as informal education of youth and adults [20].

\section{Acknowledgements}

The authors would like to appreciate the Universiti Sains Malaysia (USM) for the financial support provided for their USM-RU-Postgraduate Research Grant Scheme.

\section{References}

[1] Zhang, L., Wang, M.-H., Hu, J. and Ho, Y.-S., A review of published wetland research, 1991-2008: Ecological engineering and ecosystem restoration. Ecological Engineering 36, pp. 973-980, 2010.

[2] Wise Use of Wetlands, http://www.dpiw.tas.gov.au/inter.nsf/WebPages/ RPIO-4YS94B?open

[3] Shrestha, U., Comunity participant in wetland conservation in Nepal. The Journal of Agriculture and Environment 12, pp. 140, June 2011.

[4] UNESCO,Towards Environmentally Friendly Tourism in Arabian Biosphere Reserves: Case Study:Al Reem, Qatar. UNESCO, Doha, 2008.

[5] Andriotis, K. and Vaughan, R. D., Urban residents' attitudes toward tourism development: The case of Crete. Journal of Travel Research 42, pp. 172-185, 2003.

[6] Butler, R. W., The concept of a tourist area cycle of evolution: Implications

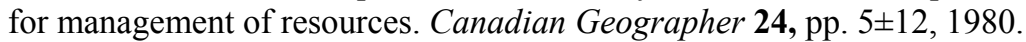

[7] Doxey, G. A., Causation theory of visitor-resident irritants: Methodology and research inferences. Travel Research Association, pp. 195-198, 1975.

[8] Improving training and public awareness on Caribbean coastal tourism. The Panos Institute and the Caribbean Institute of Media and Communication, Caribbean Environmental Network,1996.

[9] Rovelstad, J. M., Tourism training strategies and programs for the 1980s. Journal of Travel Research 21, pp. 14, 1982.

[10] McNeely, J. A., People and protected areas: Partners in prosperity. In E. Kemf (ed.) San Francisco, USA, 1993. 
[11] Environmental education and training strategy: The city of Cape Town, 2003.

[12] Gawler, M., What are best practices? Lessons in participatory management of inland and coastal wetlands, 2000.

[13] Kyle, R., Wise use of wetlands by rural indigenous people the Kosi Bay nature reserve: A case study, 1995.

[14] Wood, A.P., Afework Hailu, P.Abbot and A.Dixon, Sustainable management of wetlands in Ethiopia:Local knowledge versus government policy. Keynote Address, Second International Conference on Wetlands and Development, Dakar, November,1988.

[15] Davis, T. J. E., Towards the Wise Use of Wetlands: Convention on Wetlands. Ramsar Convention Bureau, Gland, Switzerland, 1993.

[16] Nyaupane, G. P. and Thapa, B., Perceptions of environmental impacts of tourism: A case study at ACAP, Nepal. International Journal of Sustainable Development \& World Ecology 13(1), pp. 51-61, 2006.

[17] Krahenbuhl, P. and Mullis, B., Reader on sustainable travel and tourism. Development Copyright Sustainable Travel International, pp. 2002-2006, 2007.

[18] Dolnicar, S., Crouch, G. I. and Long, P., Environment-friendly Tourists: What Do We Really Know About Them? Journal of Sustainable Tourism, 16(2), pp. 197-210, 2008.

[19] Williams, M., The human use of wetlands. Progress in Human Geography 15(1), pp. 1-22, 1991.

[20] De Klemm, C. and Créteaux, I., L'Evolution Juridique de la Convention de Ramsar $=$ The Legal Development of the Ramsar Convention $=L a$ Evolución Jurídica de la Convención de Ramsar. Ramsar Convention, Gland, Switzerland, 1995.

[21] Willoughby, N., Grimble, R., Ellenbroek, W., Danso, E. and Amatekpor, J., The wise use of wetlands: Identifying development options for Ghana's coastal Ramsar sites. Hydrobiologia 458, pp. 221-234, 2001.

[22] Tao, C.-H., Eagles, P. F. and Smith, S. L., Implications of alternative definitions of ecotourist. Tourism Analysis 9, pp. 1-13, 2004.

[23] Kerstetter, D. L., Hou, J. S. and Lin, C. H., Profiling Taiwanese ecotourists using a behavioral approach. Tourism Management 25(4), pp. 491-498, 2004. 